\title{
Congenital tufting enteropathy
}

INSERM

\section{Source}

INSERM. (1999). Orphanet: an online rare disease and orphan drug data base. Congenital tufting enteropathy. ORPHA:92050

Congenital T ufting Enteropathy is a rare congenital enteropathy presenting with earlyonset severe and intractable diarrhea that leads to irreversible intestinal failure. 